\title{
Detection of small cell lung cancer metastases in bone marrow aspirates using monoclonal antibody directed against neuroendocrine differentiation antigen
}

\author{
H H BERENDSEN,${ }^{*} \dagger$ L DE LEIJ, ${ }^{*}$ P E POSTMUS, $\dagger$ J G TER HAAR, ${ }^{*}$ S POPPEMA, $\ddagger$ \\ T H THE*
}

From the *Departments of Clinical Immunology, †Pulmonology, and $\ddagger$ Pathology, University Hospital, Groningen, The Netherlands

SUMMARY To detect metastases in the bone marrow of patients with small cell lung cancer, immunofluorescence with a monoclonal antibody detecting a membrane antigen (MOC-1) associated with small cell lung cancer was performed on 53 bone marrow aspirates from 30 patients. In $19(63 \%)$ patients MOC-1 reactive cells were detected. Simultaneous histopathological examination of the bone marrow biopsy specimens detected tumo : cells in only six (20\%).

The method is more sensitive than conventional histochemical staining of bone marrow aspirate and may eventually be able to show additional subgroups, such as patients with limited disease who might benefit from adjuvant radiotherapy or surgery.

Small cell lung carcinoma is characterised by early and widespread metastases. Combination chemotherapy is generally accepted as the treatment of choice.' Adjuvant radiotherapy can also be beneficial in some cases. Although there is no consensus about the general use of such treatment, ${ }^{23}$ a prolonged survival was noted in patients with limited stage small cell lung cancer patients who were receiving concurrent chest radiation treatment. ${ }^{4}$

To select patients without extrathoracic metastases who might benefit from combined modality treatment, staging procedures with a high sensitivity are needed for the detection of extrathoracic metastases, several procedures have been proposed. ${ }^{5}$ A common metastatic site is the bone marrow. Bone marrow disease is a negative prognostic factor. ${ }^{6}$ Most staging protocols therefore include bilateral iliac crest biopsies.

Immunohistochemical examination based on monoclonal antibodies is suitable for detecting small amounts of tumour cell invasion of the bone marrow. ${ }^{78}$ In this study we compared the standard light microscopic investigation of a posterior iliac crest biopsy specimen with immunofluorescence staining based on monoclonal antibody (MOC-1) of an aspirate obtained from the same site.

Accepted for publication 8 October 1987

\section{Material and methods}

Bone marrow aspirates and posterior iliac crest biopsy specimens were obtained during staging in patients with histologically confirmed small cell lung carcinoma. Further evaluation included routine blood cell counts, estimates of serum electrolytes, liver and renal function tests, ultrasound scan of the liver and adrenals, and isotope bone scintigraphy. Limited disease was defined as disease limited to one hemithorax, ipsilateral supraclavicular nodes, and ipsilateral pleural effusion. Tumour outside this area was defined as extensive disease. Bone marrow was aspirated from the same place or immediately adjacent to the place where biopsy specimens had been obtained. Aspirates were collected with heparinised syringes. Samples were diluted with phosphate buffered saline (Dulbecco's A, Oxoid UK) (1/1), layered over Isopaque-Ficoll, and centrifuged at $400 \mathrm{~g}$ for 20 minutes. The cell layer at the interface was collected, diluted in phosphate buffered saline, and centrifuged at $300 \mathrm{~g}$ for 10 minutes. The cell pellet was washed by an additional centrifugation step ( $200 \mathrm{~g}$ for 10 minutes) and the cells were subsequently used in a direct double immunofluorescence protocol. As a control the same technique was used on marrow aspirates obtained from six healthy volunteers.

MOC-1, ${ }^{9}$ directly labelled with fluorescein isothiocyanate ( $\mathrm{F}: \mathrm{P}$ ratio of 3 ), was used to detect metastatic small cell lung carcinoma cells. MOC-1, a 
mouse $\mathrm{IgG}_{1}$ monoclonal antibody, detects an antigen which is present on small cell lung carcinoma, and is coexpressed by different normal neuroendocrine tissues. This antigen is not present on bone marrow cells. ${ }^{9}$ The antigen recognised by this antibody was classified in small cell lung carcinoma-cluster 1 at the First International Workshop on Small Cell Lung Cancer Antigens held in London, April 1987. ${ }^{10}$ A mouse Ig $\bar{G}_{1}$ monoclonal antibody (anti-L) detecting a common leucocyte antigen $(200 \mathrm{kD})$ present on all mature lymphocytes was used as a negative control. This antibody is unreactive with other bone marrow cells. The latter monoclonal antibody was biotinilated and linked to streptavidin-Texas red. A mixture was made from MOC-1/fluorescein isothiocyanate and anti-L/Texas-red shortly before the assay. After incubation of isolated bone marrow cells with the monoclonal antibody preparation $\left(4^{\circ} \mathrm{C}\right.$ for $60 \mathrm{~min}$ utes) the cells were washed three times in phosphate buffered saline by centrifugation and subsequently fixed in paraformaldehyde $1 \%(\mathrm{w} / \mathrm{v})$. About $10^{4}$ cells were screened for fluorescence in each preparation. Cells from a small cell lung carcinoma derived cell line (GLC-8) were always used as a positive control.

Some of the isolated bone marrow cells were incubated at $37^{\circ} \mathrm{C}$ in $5 \%$ carbon dioxide in a humidified atmosphere in Hites medium, " supplemented with $3 \%$ fetal calf serum.

\section{Results}

Fifty three immunofluorescence assays were performed on the bone marrow aspirates from 30 patients. In 23 patients bilateral and in seven patients unilateral aspirates were studied. In 19 patients $(63 \%)$ cells reacting with MOC-1 but non-reactive with the control monoclonal antibody were found (fig 1). All patients with bone marrow metastases detected in the posterior iliac crest biopsy specimen by conventional light microscopy $(n=6)$ showed positive immunofluorescence with MOC-1. In four patients biopsy specimens and aspirates were investigated before as well as immediately after chemotherapy. Persistent marrow disease detectable only by immunofluorescence was noted in one patient. In 13 patients with limited disease, seven (54\%) bone marrow aspirates contained cells reactive with MOC-1. Of the 17 patients with extensive disease $12(71 \%)$ were positive.

No MOC-1 reactive cells were found in the marrow aspirates obtained from the six healthy volunteers. From 12 aspirates containing MOC-1 reactive cells, which had been obtained from patients with normal bone marrow histological results, a sample was put into tissue culture medium. A small cell lung carcinoma cell line (GLC-25) was established from one of these. This patient had limited disease according to routine staging criteria.

\section{Discussion}

On morphological criteria alone it is difficult to identify one or a few tumour cells in a bone marrow biopsy or smear. Staining with monoclonal antibodies may improve the recognition of such a micrometastasis because a single tumour cell can be specifically visualised. ${ }^{7}$ An additional advantage of the immunofluorescence protocol described here is that the procedure permits the use of a suspension rather than a section, cytospin, or cell smear, so larger amounts of cells may be screened more easily. This application relies on proper recognition of the tumour cells. Damaged cells and small contaminations with bone marrow lipids which are not removed by the gradient centrifugation, might produce non-specific staining in the immunofluorescence assay. In the protocol described in this paper, we therefore included a control monoclonal antibody to detect possible non-specific staining. Only those cells reactive with MOC-1 alone were scored as positive.

Bone marrow metastases can be detected by conventional light microscopy in up to $45 \%$ of patients with small cell lung carcinoma. ${ }^{12}$ Immunoreactivity with MOC-1, suggesting bone marrow metastases, was found in $63 \%$ of the patients in our study. A large proportion of them $(54 \%)$, who otherwise were staged as limited disease, had MOC-1 positive cells in their bone marrow aspirates. The percentage is clearly higher than that obtained by conventional light microscopy. These results agree with those obtained by Stahel et al. ${ }^{8}$ In contrast, no cases of occult micrometastases were detected in a series of 11 patients with small cell lung carcinoma and 26 patients with non-small cell lung carcinoma using monoclonal antibodies directed against intermediate filaments. ${ }^{13}$ An increased detection of bone marrow metastases has been noted in other solid tumours, when monoclonal antibody guided staining techniques were compared with conventional bone marrow stains. ${ }^{14-17}$ In patients with breast cancer ${ }^{1415}$ metastases were found in $60 \%$ of marrows which had been reported to be free of tumour by conventional light microscopy, and in neuroblastoma ${ }^{16}$ the detection of metastatic tumour increased from $27 \%$ to $74 \%$.

Although MOC-1 reacts with small cell lung carcinoma and is unreactive with normal or regenerating bone marrow, it is difficult to prove that a single cell reacting with MOC-1 is a tumour cell: two observations are in favour of such a conclusion. Firstly, all bone marrow samples containing metastases on conventional light microscopy were also found to be reactive with MOC-1 and, secondly, a small cell lung 

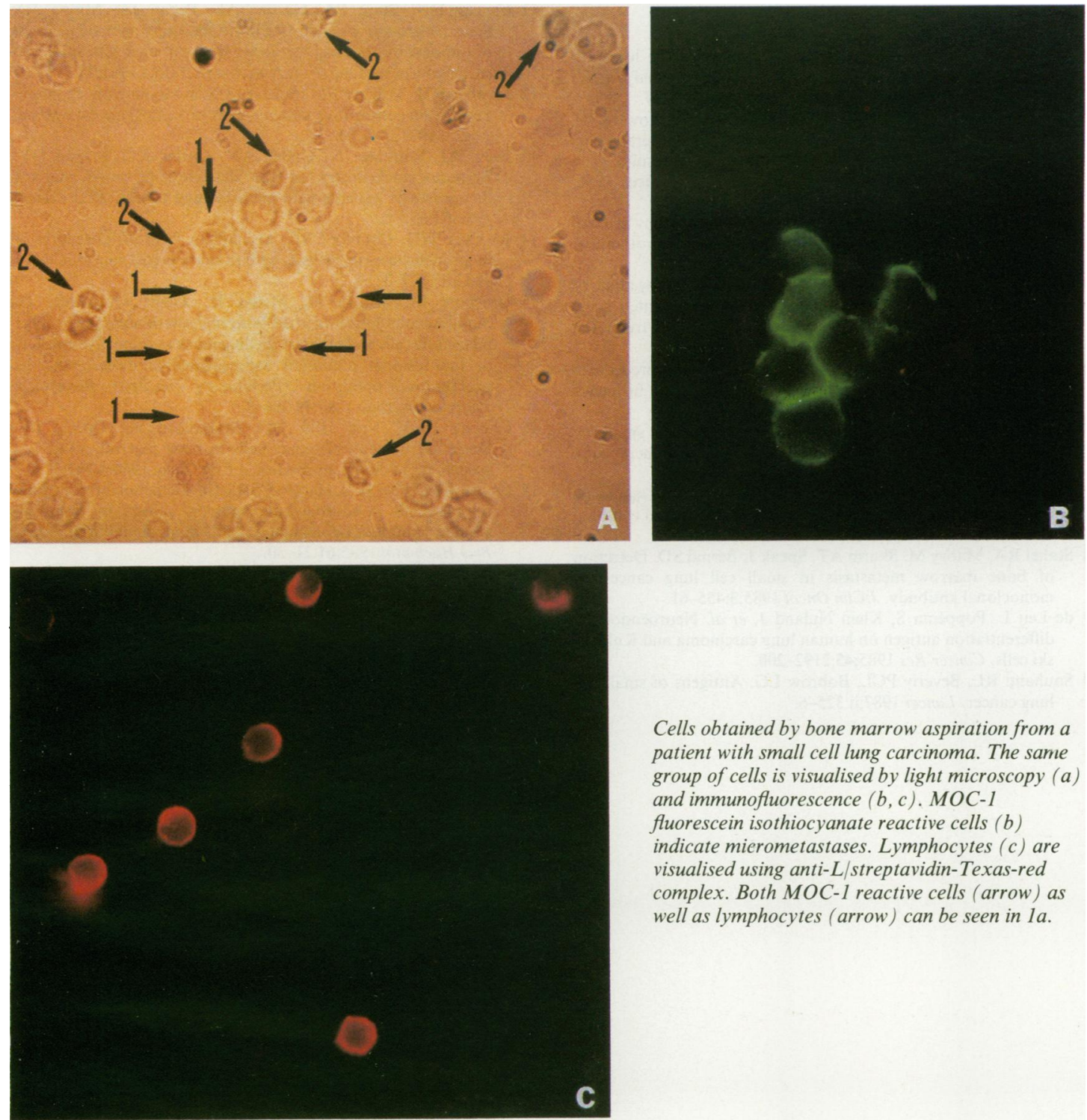

Cells obtained by bone marrow aspiration from a patient with small cell lung carcinoma. The same group of cells is visualised by light microscopy (a) and immunofluorescence $(b, c)$. MOC-1

fluorescein isothiocyanate reactive cells (b) indicate mierometastases. Lymphocytes (c) are visualised using anti-L/streptavidin-Texas-red complex. Both MOC-1 reactive cells (arrow) as well as lymphocytes (arrow) can be seen in la.

carcinoma cell line was established from a bone marrow which was tumour free according to the conventional light microscopical evaluation, but showed MOC-1 reactive cells.

After performing non-invasive staging procedures conventional histochemical staining of bone marrow does not show additional subgroups. ${ }^{18}$ The more sensitive detection of bone marrow metastases using the technique described here may eventually indicate such a patient category. This is of particular impor- tance for patients with limited disease, who also have bone marrow free of metastases, as judged by a negative immunofluorescence, and who might be candidates for adjuvant radiotherapy, or surgery, or both after the induction of a remission by combination chemotherapy.

This study was supported by a grant from the Koningin Wilhelmina Fonds. 


\section{References}

1 Minna JD, Higgins GA, Glatstein EJ. Cancer of the lung. In: Devita VT, Hellman S, Rosenberg S, eds. Principles and practice of oncology. Philadelphia: D Lippincott, 1985:507-97.

2 Osterlind K, Hansen HH, Hansen HS, Dombernowsky P, Hansen M, Rorth M. Chemotherapy versus chemotherapy plus irradiation in limited small cell lung cancer: results of a controlled trial with 5 years follow-up. Br J Cancer 1986; 54:7-17.

3 Souhami RL, Geddes DM, Spiro SG, et al. Radiotherapy in small cell cancer of the lung treated with combination chemotherapy: a controlled trial. Br Med J 1984;288:1643-6.

4 Bunn PA, Lichter AS, Makuch RW, et al. Chemotherapy alone or chemotherapy with chest radiation therapy in limited stage small cell lung cancer. A prospective, randomised trial. Ann Intern Med 1987;106:655-22.

5 Hansen HH, Dombernowsky P, Hirsch FR. Staging procedures and prognostic features in small cell anaplastic bronchus carcinoma. Semin Oncol 1978;5:280-7.

6 Hirsch FR, Hansen HH. Bone marrow involvement in small cell anaplastic carcinoma of the lung: prognostic and therapeutic aspects. Cancer 1980;46:206-11.

7 Postmus PE, Hirschler-Schulte CJW, de Ley L. Diagnostic application of a monoclonal antibody against small cell lung cancer. Cancer 1986;57:60-3.

8 Stahel RA, Mabry M, Skarin AT, Speak J, Bernal SD. Detection of bone marrow metastasis in small cell lung cancer by monoclonal antibody. J Clin Oncol 1985;3:455-61.

9 de Leij L, Poppema S, Klein Nuland J, et al. Neuroendocrine differentiation antigen on human lung carcinoma and Kulchitski cells. Cancer Res 1985;45:2192-200.

10 Souhami RL, Beverly PCL, Bobrow LG. Antigens of small-cell lung cancer. Lancet 1987;ii:325-6.
11 Carney DN, Bunn PA, Gazdar AF, Pagan JA, Minna JD. Selective growth in serum-free hormone-supplemented medium of tumor cells obtained by biopsy from patients with small cell carcinoma of the lung. Proc Natl Acad Sci USA 1981;78:3185-9.

12 Hansen HH, Muggia FM, Selawry OS. Bone-marrow examination in 100 consecutive patients with bronchogenic carcinoma. Lancet 1971;ii:443-5.

13 Frew AJ, Ralfkiaer N, Ghosh AK, Gatter KC, Mason DY. Immunocytochemistry in the detection of bone marrow metastases in patients with primary lung cancer. $\mathrm{Br} J$ Cancer 1986;53:555-6.

14 Redding WH, Coombes RC, Monaghan P, et al. Detection of micrometastases in patients with primary breast cancer. Cancer 1983;ii:1271-3.

15 Ginsburg M, Musset M, Misset JL, Genty O, Mathé G. Simultaneous detection in the bone marrow of mammery cancer metastatic cells and of their labelling index as respective markers of the residual minimum submacroscopic disease and its proliferative condition (Preliminary results). Biomedical Pharmacotherapy 1986;40:386-8.

16 Cheung NKV, Von Hoff DD, Strandjord SE, Coccia PF. Detection of neuroblastoma cells in bone marrow using $\mathrm{G}_{\mathrm{D} 2}$ specific monoclonal antibodies. J Clin Oncol 1986;4:363-9.

17 Ghosh AK, Erber WN, Hatton CSR, et al. Detection of metastatic tumour cells in routine bone marrow smears by immunoalkaline phophotase labelling with monoclonal antibodies. Br J Haematol 1985;61:21-30.

18 Campling B, Quirt I, DeBoer G, Feld R, Shepherd FA, Evans WK, Is bone marrow examination in small-cell lung cancer really necessary? Ann Intern Med 1986;105:508-12.

Requests for reprints to: $\mathrm{Dr} \mathrm{HH}$ Berendson, Department of Clinical Immunology, University Hospital, Oostersingel 59, 9713 EZ Groningen, The Netherlands. 